Journal of Environmental Engineering and Science Volume 10 Issue JS3

Nutrient recovery from foam with microwave treatment

More, Srinivasan, Liao et al.
Journal of Environmental Engineering and Science, 2015, 10(3), 53-61 http://dx.doi.org/10.1680/jenes. 15.00005 Paper 15.00005

Received 25/04/2015; accepted 16/10/2015

Published online 10/11/2015

Keywords: environment/sewage treatment \& disposal/thermal effects

ICE Publishing: All rights reserved iten

\title{
Nutrient recovery from foam with microwave treatment
}

Abhilasha More MEng

Graduate Student, Department of Civil Engineering, University of British Columbia, Vancouver, Canada

Asha Srinivasan PhD

Research Fellow, Department of Civil Engineering, University of British Columbia, Vancouver, Canada

Ping Huang Liao PhD

Research Associate, Department of Civil Engineering, University of British Columbia, Vancouver, Canada
Fred Koch MSC

Research Associate, Department of Civil Engineering, University of British Columbia, Vancouver, Canada

Donald S. Mavinic PhD

Professor, Department of Civil Engineering, University of British Columbia, Vancouver, Canada

\section{Kwang Victor Lo PhD}

Professor, Department of Civil Engineering, University of British Columbia, Vancouver, Canada (corresponding author: kvlo@civil.ubc.ca)

Phosphorus recovery and solids reduction potential from foam generated in the anoxic reactor of membrane-enhanced biological phosphorus removal system were studied using the microwave-enhanced advanced oxidation process ( $\mathrm{MW} / \mathrm{H}_{2} \mathrm{O}_{2}$-AOP). The $\mathrm{MW} / \mathrm{H}_{2} \mathrm{O}_{2}$-AOP-treated foam at different experimental conditions showed significant improvement in solubilisation of orthophosphate, ammonia, volatile fatty acids and soluble chemical oxygen demand as well as settling and dewatering ability. The most significant factors maximising orthophosphate release in the order of most to least affecting were (i) microwave heating temperature, (ii) combined effect of microwave heating temperature and hydrogen peroxide addition and (iii) addition of sulfuric acid. At temperature $180^{\circ} \mathrm{C}, \mathrm{pH} 3$ and hydrogen peroxide dosage $0.5 \% \mathrm{v} / \mathrm{v}$, nutrient solubilisation, settling, and dewatering properties were at their maximum with $67 \%$ of the total phosphate solubilised as orthophosphate.

\section{Introduction}

Foaming is observed to be a common operational problem in conventional activated sludge processes. Some wastewater treatment plants (WWTP) have skimmers to remove foam from the surface; still part of it escapes with the effluent, reducing its quality (Di Bella et al., 2011). Foam is a composition of gas bubbles (mostly nitrogen by denitrification or carbon dioxide produced by biological reactions in the reactors), solids, microorganisms and liquid (Hall et al., 2011). Therefore, solids-liquid separation of foam is difficult due to the characteristics of the material. Even though the exact physical and biological mechanism initiating foam formation and stabilisation remains unanswered, it is generally associated with two bacterial genera, the nocardioforms types named Gordonia amarae and Candidatus Microthrix parvicella (M. parvicella) (Di Bella et al., 2011; Fryer et al., 2011). The filamentous bacteria like M. parvicella or Nocardia amarae can accumulate or release phosphorus in aerobic and anaerobic conditions. Microbes observed in the foam can accumulate about $20 \%$ more phosphorus than that of the phosphorus-accumulating organisms like Acinetobacter calcoaceticus (Suschka et al., 2009). Filamentous microorganisms present in the foam can be a potential source for recovering phosphates, nitrogen compounds, potassium, magnesium and calcium cations owing to their ability to uptake and accumulate polyphosphates and metal cations in volutin granules (Machnicka et al., 2008). Characterisation studies done on anoxic foam and mixed liquor from anoxic reactor in membrane-enhanced biological phosphorus removal (MEBPR) showed similar chemical composition in addition to ten times more suspended solids and much higher concentrations of TP, total nitrogen and metals (Lo et al., 2010). Activated sludge from MEBPR is very difficult to settle and concentrate, while it is relatively easy to collect foam from MEBPR. In addition, regular harvesting of foam has potential to control solids retention time (SRT) and minimise foam accumulation in the system along with being a rich source of phosphorus that could be recovered from a side stream recovery process (Hall et al., 2011). Removal of these nutrients in the form of struvite (slow nutrient releasing fertiliser) can be achieved by a crystallisation process (Le Corre et al., 2009; Mavinic et al., 2007).

The microwave (MW)-enhanced advanced oxidation $\left(\mathrm{MW} / \mathrm{H}_{2} \mathrm{O}_{2^{-}}\right.$ AOP) was developed by the Environmental Engineering team at the University of British Columbia (UBC) for the treatment of organic slurries. It is a dielectric heating process, in which electromagnetic radiation from MW interacts with dielectric materials generating heat (Lo et al., 2011). Hydrogen peroxide $\left(\mathrm{H}_{2} \mathrm{O}_{2}\right)$ is a strong oxidiser depending on the $\mathrm{pH}$ of the solution and synergistic effect between MW heating temperature and hydrogen peroxide dosage produce significant conversion of polyphosphates to orthophosphates (Ortho-P). It has been observed that the combination of MW irradiation and hydrogen peroxide oxidant achieves efficient solubilisation of nutrients in treated foam, sewage sludge and agricultural wastes such as dairy manure and fish silage. It also proved to be effective in solids reduction by enhanced hydrolysis of organic solids (Lo et al., 2011; Yawson et al., 2011; Yin et al., 2007; Yu et al., 2010). Subsequent to $\mathrm{MW} / \mathrm{H}_{2} \mathrm{O}_{2}-\mathrm{AOP}$, further solids handling is more efficient 
compared to anaerobic digestion (Lo et al., 2011). Biosolids processing currently involves almost half of the total cost for wastewater treatment due to its health and environmental impacts (Yu et al., 2010). Since biosolids are planned to be diverted from landfills, there is an urgent need to address their treatment and disposal issues. Similarly, use of the biosolids in agriculture is also restricted due to potential contamination of soil by persistent organic pollutants found in wastewater (Ahrens et al., 2009; Sepulvado et al., 2011; Weinberg et al., 2011).

Foam generated in MEBPR plant showed 100\% release of total phosphorus (TP) to supernatant after $\mathrm{MW} / \mathrm{H}_{2} \mathrm{O}_{2}$-AOP treatment at $160^{\circ} \mathrm{C}$ along with other nutrients such as nitrogen, potassium, magnesium, and calcium (Lo et al., 2010). Additionally, $\mathrm{MW} / \mathrm{H}_{2} \mathrm{O}_{2}$ AOP treatment of foam exhibited seven times more solids disintegration in terms of total chemical oxygen demand (TCOD) than treated mixed liquor (Hall et al., 2011; Lo et al., 2010). Therefore, foam can be a better suitable substrate than sludge for MW process and a resource, instead of being a nuisance, by recovering nutrients and reducing solids handling burden in WWTP. So far, nutrient recovery potential from foam has not been explored in detail. Lo et al. (2010) studied the $\mathrm{MW} / \mathrm{H}_{2} \mathrm{O}_{2}$-AOP treatment of foam at relatively lower temperature with $(\mathrm{pH} \sim 2)$ and without $\mathrm{pH}$ adjustment. Such studies on $\mathrm{MW} / \mathrm{H}_{2} \mathrm{O}_{2}$-AOP treatment of foam were conducted when the SRT at MEBPR was as low as $10 \mathrm{~d}$; however, during recent operations, the SRT has been increased to as high as $25 \mathrm{~d}$. Therefore, there is a need to study the nutrient release and solids disintegration potential of $\mathrm{MW} / \mathrm{H}_{2} \mathrm{O}_{2}-\mathrm{AOP}$ treated foam obtained from the modified MEBPR process. For this purpose, a detailed response surface methodology (RSM) has been carried out in this study.

The objectives of this study were to examine the effect of $\mathrm{MW} / \mathrm{H}_{2} \mathrm{O}_{2}-\mathrm{AOP}$ on the characteristics of foam such as total and suspended solids content, orthophosphorus concentration, ammonia, and so on, and to determine the most significant factors (temperature, $\mathrm{pH}$ and hydrogen peroxide dosage) on nutrient solubilisation, solids disintegration, settling and dewatering ability of the treated foam.

\section{Materials and methods}

Feed

The present study was conducted on foam collected from the anoxic reactor in the Staging Environmental Research Centre (SERC), located at the south campus of UBC, which operates on municipal wastewater. The SERC is a dual train pilot scale facility based on modified University of Cape Town - MBR design and utilises MEBPR process. The details of the MEBPR at SERC are provided in detail by Hall et al. (2011). Owing to porous nature of foam, samples were prepared on weight basis. The MEBPR was operated at an SRT of 25d, and a hydraulic retention time (HRT) of $10 \mathrm{~h}$.

\section{$\mathrm{MW} / \mathrm{H}_{2} \mathrm{O}_{2}-\mathrm{AOP}$}

Microwave treatment was applied with the closed-vessel MW digestion system (Ethos TC Digestion Lab station 5000, Milestone
Inc., USA) with an operating frequency of $2450 \mathrm{MHz}$ and a maximum power supply of $1000 \mathrm{~W}$ (Kenge et al., 2009; Lo et al., 2010). To accommodate pressure built up at high operating temperature in a closed vessel system, the weight of each foam sample was maintained to $30 \mathrm{~g}$ in each set of experiments. A $30 \%$ hydrogen peroxide was used as an oxidant and for each single run hydrogen peroxide dosage was calculated on volume/volume basis with volume of foam calculated from its density collected for each run.

\section{Experimental design}

Based on past research on the $\mathrm{MW} / \mathrm{H}_{2} \mathrm{O}_{2}$-AOP, key factors chosen for optimisation of the treatment were MW temperature, hydrogen peroxide dosage and acid addition (Kenge et al., 2009; Wong et al., 2007). Control experiments to determine the importance of acid addition and MW heating alone on foam characteristics were first carried out (Table 1). MW/ $\mathrm{H}_{2} \mathrm{O}_{2}$-AOP treatment in acidic conditions yielded best results for dewaterability along with nutrient release than alkaline conditions (Chan et al., 2010). Therefore, MW heating temperature, hydrogen peroxide dosage and $\mathrm{pH}$ (controlled by sulfuric acid addition) were the factors chosen for the response surface study (Table 2), to determine its significance and effect on phosphorus and ammonia solubilisation, solids destruction, settling and dewatering ability of the foam. The RSM was created with a built-in model from statistical software package JMP 11.0.0 (SAS, 2013). The three-factor-three-level surface response design included (i) MW heating temperature $\left(120,160,180^{\circ} \mathrm{C}\right)$; (ii) $\mathrm{pH} 3$, $\mathrm{pH} 4$ and no acid addition; and (iii) hydrogen peroxide dosage $(0 \cdot 1,0 \cdot 3,0 \cdot 5 \% \mathrm{v} / \mathrm{v}) . \mathrm{RSM}$ is a technique to find the optimal response within the specified range of the factors, which is capable of fitting a second-order prediction equation for the response. A total of nine runs were conducted by varying the three factors (Table 2). A triplicate of the $\mathrm{MW} / \mathrm{H}_{2} \mathrm{O}_{2}$-AOP-treated sample was used for each parameter analysis. Before MW heating, 20\% dilute sulfuric acid was added until the desired $\mathrm{pH}$ was obtained and $30 \%$ hydrogen peroxide was added to desired quantity. Samples were then heated at a rate of $20^{\circ} \mathrm{C} / \mathrm{min}$ until the target temperature was achieved and held for $5 \mathrm{~min}$ at that temperature for each set of experiment.

\section{Analysis}

Initial conditions of SRT and HRT were obtained from the UBC pilot plant. Procedures outlined in Standard Methods were followed for analysis of treated and untreated samples (APHA et al., 2005). The total portion of the untreated and treated samples were analysed for total solids (TS), TCOD, TP, and total Kjeldahl nitrogen (TKN). Untreated and treated samples were centrifuged at $6000 \mathrm{rpm}$ for $10 \mathrm{~min}$ and the supernatant was filtered through $0 \cdot 45 \mu \mathrm{m}$ Whatman filter paper. Filtered supernatant was analysed for soluble chemical oxygen demand (SCOD), Ortho-P, ammonia, volatile fatty acids (VFA) and metals. Inductively coupled plasma mass spectrometer (ICP-MS) was used for calcium, potassium, magnesium and sodium analyses.

The details of chemical analysis for TP, ortho-P, ammonia, TKN and VFAs are explained elsewhere (Lo et al., 2010). Sludge 


\begin{tabular}{|c|c|c|c|c|c|c|c|}
\hline Run & MW-Temp: ${ }^{\circ} \mathrm{C}$ & $\mathrm{pH}$ & $\mathrm{H}_{2} \mathrm{O}_{2}: \% v / v$ & Run & MW-Temp: ${ }^{\circ} \mathrm{C}$ & $\mathrm{pH}$ & $\mathrm{H}_{2} \mathrm{O}_{2}: \% \mathrm{v} / \mathrm{v}$ \\
\hline A & - & 5 & 0 & 1 & 120 & $7^{a}$ & 0.5 \\
\hline B & 160 & $7^{a}$ & 0 & 2 & 120 & 4 & 0.3 \\
\hline C & 120 & 4 & 0 & 3 & 120 & 3 & $0 \cdot 1$ \\
\hline D & 160 & 4 & 0 & 4 & 160 & $7^{a}$ & $0 \cdot 1$ \\
\hline $\mathrm{E}$ & 180 & 4 & 0 & 5 & 160 & 4 & 0.5 \\
\hline $\mathrm{F}$ & 120 & 3 & 0 & 6 & 160 & 3 & 0.3 \\
\hline G & 160 & 3 & 0 & 7 & 180 & $7^{a}$ & $0 \cdot 3$ \\
\hline \multirow[t]{2}{*}{$\mathrm{H}$} & 180 & 3 & 0 & 8 & 180 & 4 & $0 \cdot 1$ \\
\hline & & & & 9 & 180 & 3 & 0.5 \\
\hline
\end{tabular}

${ }^{\mathrm{a}} \mathrm{No} \mathrm{pH}$ adjustment by acid addition for these run.

Table 1. Conditions for control experiments and surface response experimental design

\begin{tabular}{|c|c|c|c|c|c|c|}
\hline Run & Ortho-P: mg/L & Ortho-P/TP: \% & $\mathrm{NH}_{3}: \mathrm{mg} / \mathrm{L}$ & Total VFA': mg/L & SCOD: $g / L$ & SCOD/TCOD: \% \\
\hline Raw & $142 \cdot 5 \pm 61$ & $9 \cdot 6$ & $18 \pm 7$ & $43 \cdot 8 \pm 8 \cdot 5$ & $0.1 \pm 0.04$ & $0 \cdot 3$ \\
\hline A & $252 \cdot 9 \pm 39$ & $20 \cdot 7$ & $29 \cdot 6 \pm 3$ & $8 \cdot 1 \pm 1$ & $0.2 \pm 0.01$ & 0.6 \\
\hline$B$ & $482 \cdot 3 \pm 71$ & $41 \cdot 4$ & $40 \cdot 4 \pm 0.86$ & - & - & - \\
\hline C & $338 \cdot 3 \pm 8$ & $17 \cdot 6$ & $19 \cdot 1 \pm 1$ & $61 \cdot 3$ & $3 \cdot 4 \pm 0 \cdot 2$ & 9 \\
\hline $\mathrm{D}$ & $623 \cdot 3 \pm 28$ & $33 \cdot 3$ & $32 \cdot 8 \pm 4$ & $82 \cdot 7$ & $6.6 \pm 0.8$ & $17 \cdot 6$ \\
\hline$E$ & $591 \cdot 7 \pm 1$ & $44 \cdot 6$ & $34 \cdot 5 \pm 2$ & $168 \cdot 6 \pm 12$ & 10 & $25 \cdot 7$ \\
\hline $\mathrm{F}$ & $230 \cdot 4 \pm 39$ & $19 \cdot 7$ & $21 \cdot 9 \pm 2$ & $72 \cdot 9 \pm 7$ & $4 \cdot 8 \pm 0 \cdot 2$ & $13 \cdot 4$ \\
\hline G & $578 \cdot 8 \pm 94$ & $49 \cdot 6$ & $24 \cdot 1 \pm 3$ & $114 \cdot 7 \pm 6$ & $5 \cdot 7 \pm 0.6$ & $15 \cdot 6$ \\
\hline $\mathrm{H}$ & $634 \cdot 6 \pm 45$ & $54 \cdot 4$ & $28 \cdot 3 \pm 3$ & $120 \cdot 8 \pm 16$ & $6 \cdot 8 \pm 0 \cdot 5$ & $17 \cdot 5$ \\
\hline 1 & $374 \cdot 2 \pm 39$ & $25 \cdot 2$ & $85 \cdot 4 \pm 3$ & $289 \pm 10$ & $11 \cdot 1 \pm 0 \cdot 3$ & $27 \cdot 3$ \\
\hline 2 & $385 \cdot 8 \pm 83$ & $21 \cdot 1$ & $53 \cdot 3 \pm 14$ & $114 \cdot 8 \pm 9$ & $7 \cdot 3 \pm 1$ & $23 \cdot 2$ \\
\hline 3 & $584 \cdot 2 \pm 31$ & $32 \cdot 6$ & $44 \cdot 1 \pm 4$ & $120 \cdot 2 \pm 15$ & $6 \cdot 4 \pm 2 \cdot 3$ & $17 \cdot 7$ \\
\hline 4 & $419 \cdot 2 \pm 57$ & $32 \cdot 6$ & $46 \cdot 5 \pm 3$ & $248 \cdot 6 \pm 43$ & $9 \cdot 8 \pm 1 \cdot 2$ & $25 \cdot 1$ \\
\hline 5 & $880 \pm 38$ & $52 \cdot 6$ & $153 \cdot 3 \pm 15$ & $195 \cdot 3 \pm 12$ & $15 \pm 0.6$ & $33 \cdot 3$ \\
\hline 6 & $828 \cdot 8 \pm 117$ & $63 \cdot 7$ & $85 \cdot 9 \pm 6$ & $169 \cdot 6 \pm 24$ & $7 \cdot 7 \pm 0 \cdot 8$ & $22 \cdot 9$ \\
\hline 7 & $621 \cdot 7 \pm 34$ & $44 \cdot 0$ & $132 \cdot 8 \pm 13$ & $344 \cdot 1 \pm 42$ & $15 \cdot 2 \pm 1$ & $28 \cdot 4$ \\
\hline 8 & $692 \cdot 5 \pm 31$ & 54 & $69 \cdot 4 \pm 5$ & $239 \cdot 2 \pm 9$ & $14 \cdot 4 \pm 1 \cdot 4$ & $36 \cdot 3$ \\
\hline 9 & $1160 \pm 131$ & $67 \cdot 3$ & $213 \cdot 3 \pm 21$ & $360 \cdot 7 \pm 13$ & $14 \cdot 9 \pm 0 \cdot 8$ & $36 \cdot 4$ \\
\hline
\end{tabular}

-Not included in the table due to analytical problems; ${ }^{\text {total }}$ VFAs expressed as acetic acid equivalents.

Table 2. Results from control experiments and surface response experimental design

dewatering ability was analysed by $2710 \mathrm{G}$ capillary suction time (CST) method using the Komline-Sanderson capillary suction timer (Komline-Sanderson Engineering Corporation, Peapack, New Jersey, USA). The instrument includes a paper support block, stainless-steel reservoir with $18 \mathrm{~mm}$ inner dia. and $25 \mathrm{~mm}$ height, and a digital timer. Settling ability of treated foam was analysed with $60 \mathrm{~min}$ settling test. Particle-size distribution analysis was performed with Malvern Mastersizer 2000 (Hydro 2000S) particle size analyser.

\section{Results and discussion}

An ortho-P/TP ratio of $9.5 \%$, ammonia-to-TKN ratio of $0.53 \%$, and SCOD/TCOD ratio of $0 \cdot 26 \%$ was observed in the raw foam samples. TS content of the untreated sample was $3 \cdot 3 \% \pm 0 \cdot 4$ with $0.9 \pm 0.04 \mathrm{~g} / \mathrm{mL}$ of density and $\mathrm{pH}$ of $6.9 \pm 0.4$.

\section{Control experiments}

Control experiments were performed to understand the significance of combination of acid addition with MW heating and only 
MW heating without acid or hydrogen peroxide on ortho-P release (Table 1). The results of these experiments are presented in Table 2. On average, TS of $3 \cdot 5 \%$ and TCOD of approximately $40 \mathrm{~g} / \mathrm{L}$ were recorded after treatment for all experimental runs, which was equivalent to TCOD/TS ratio of $1 \cdot 1$. The treatment resulted in TP of $1531 \pm 225 \mathrm{mg} / \mathrm{L}$ and TKN of $3375 \pm 830 \mathrm{mg} / \mathrm{L}$.

About $41.4 \%$ of phosphorus was released with MW treatment alone. MW heating at all three temperatures of 120,160 and $180^{\circ} \mathrm{C}$ at acidic $\mathrm{pH}(\mathrm{pH} 3$ and 4) without any addition of hydrogen peroxide resulted in high phosphate release. Orthophosphate increased with an increasing temperature. Combined effect of MW heating temperature and low $\mathrm{pH}$ resulted in higher phosphate solubilisation. However, no substantial effect on ammonia release was observed.

The results from control experiments can be concluded that (i) MW heating with no acid and hydrogen peroxide, (ii) acid addition till $\mathrm{pH}$ 5, and (iii) MW treatment at $\mathrm{pH} 4$ without hydrogen peroxide, did not affect nutrient solubilisation. Control experiment results and results from the earlier studies clearly indicated the importance of hydrogen peroxide addition to improve nutrient release and solubilisation of carbonaceous matter (Liao et al., 2007; Lo et al., 2010). Therefore, hydrogen peroxide dosage was chosen to be important variable in the RSM experimental design.

\section{Surface response experiments}

Nutrient release

Orthophosphate: Phosphorus is mostly present as ortho-P, pyrophosphate and polyphosphate in wastewater. With increase in SRT, phosphorus is retained in the system forming more stable and longer chain polyphosphates and foam has the ability to accumulate more phosphorus than mixed liquor (Lo et al., 2010). $\mathrm{MW} / \mathrm{H}_{2} \mathrm{O}_{2^{-}}$ AOP treatment of different organic slurries like sewage sludge, waste-activated sludge, foam, dairy manure, and so on showed these polyphosphates to solubilise into a simpler ortho-P form (Chan et al., 2010; Lo et al., 2011; Yu et al., 2010). Similar trend was observed in the current study, and the results of phosphate solubilisation are presented in Table 2. Conversion of polyphosphates to Ortho-Ps through hydrolysis is enhanced at higher temperature and acidic conditions. Ortho-P release was significant after MW treatment and increased with increase in MW heating temperature irrespective of addition of hydrogen peroxide or sulfuric acid. A minimum of $385 \cdot 8 \pm 83 \mathrm{mg} / \mathrm{L}$ to a maximum $1160 \pm 131 \mathrm{mg} / \mathrm{L}$ of Ortho-P was released after treatment corresponding to $21-67 \%$ of the TP content in the treated samples, respectively. A maximum phosphorus release into solution was observed at $180^{\circ} \mathrm{C}$ with $0 \cdot 5 \% \mathrm{v} / \mathrm{v}$ hydrogen peroxide and at $\mathrm{pH} 3$.

The pareto plot generated for the experimental sets is given in Figure 1 and the experimental results are presented in Table 2. Pareto plots are charts displaying the relative frequency or severity of effects in a quality-related process or operation and initially displayed as a bar chart that shows the significance of parameters arranged in decreasing order. As seen from Figure 1(a), the three most significant factors maximising ortho-P release, from the most to least order of significance, were as follows: (i) MW heating temperature, (ii) combined effect of MW heating temperature and hydrogen peroxide addition, and (iii) lower $\mathrm{pH}$ that is addition of sulfuric acid. MW heating temperature was the most significant factor in phosphate solubilisation in agreement with the results from previous studies (Lo et al., 2010; Wong et al., 2007). The results of nine experimental run provide a good acceptable fit to the data with $R^{2}$ value of 0.99 .

Ammonia: Results for ammonia release observed after the $\mathrm{MW} / \mathrm{H}_{2} \mathrm{O}_{2}$-AOP are shown in Table 2. A minimum ammonia concentration of $44 \cdot 1 \pm 4 \mathrm{mg} / \mathrm{L}$ was observed in the treated solution at experimental conditions $120^{\circ} \mathrm{C}, \mathrm{pH} 3$ and $0 \cdot 1 \% \mathrm{v} / \mathrm{v}$ hydrogen peroxide dosage; whereas, the maximum yield of $213.3 \pm 21 \mathrm{mg} / \mathrm{L}$ was recorded at $180^{\circ} \mathrm{C}$, pH 3 and $0.5 \% \mathrm{v} / \mathrm{v}$ hydrogen peroxide dosage. With $R^{2}$ value of 0.98 , the results for ammonia release provided a good fit to the data. The three significant factors playing key role in ammonia release, in an order from the most to least significance, were as follows: (i) MW heating temperature, (ii) hydrogen peroxide dosage and (iii) combined effect of MW heating and hydrogen peroxide addition (Figure 1(b)). Similar to ortho-P, MW heating temperature was the most significant factor in ammonia yield followed by hydrogen peroxide dosage. However, hydrogen peroxide dosage was observed to be the most significant parameter in ammonia release in sewage sludge (Kenge et al., 2009; Wong et al., 2007). The difference could be due to the low hydrogen peroxide dosage $(0 \cdot 1-0.5 \% \mathrm{v} / \mathrm{v})$ used in the current study compared with previous studies. Maximum ammonia release corresponded to only $8 \cdot 7 \%$ of TKN, but it was substantial compared to the ammonia content in initial foam sample. During $\mathrm{MW} / \mathrm{H}_{2} \mathrm{O}_{2}$-AOP, ammonia was increased due to thermal destruction of microorganisms, and the breakdown of large organic molecules from TKN was enhanced in the presence of oxidants like hydrogen peroxide and/or ozone (Yin et al., 2008). After the MW/ $\mathrm{H}_{2} \mathrm{O}_{2}$-AOP treatment, large amounts of intracellular materials were released from microbial cell destruction and nitrogen may be present in solubilised forms such as soluble protein and/or amino acids (Yi et al., 2014) and amount of oxidants used play an important role in further breakdown of these compounds to ammonia (Lo et al., 2010; Yin et al., 2007).

\section{Solids disintegration}

SCOD: MW heating temperature was found to be the key factor in increasing SCOD yield (Table 2). The three significant factors affecting SCOD release were as follows in the order from most to least significant: (i) MW heating temperature, (ii) hydrogen peroxide addition, and (iii) sulfuric acid addition; the findings were in line with previous observations (Lo et al., 2010; Yin et al., 2008). Higher values for SCOD and increased SCOD/TCOD ratios were indicators of solids disintegration. Biomass from foam was broken down after digestion depending on the experimental conditions; part of it was solubilised resulting in an increasing SCOD value. SCOD values in current study ranged from $6 \cdot 4 \pm 2 \cdot 3$ to $14 \cdot 9 \pm 0 \cdot 8 \mathrm{~g} / \mathrm{L}$, corresponding to $17 \cdot 7 \%$ and $36 \cdot 4 \%$ of TCOD, respectively. The 


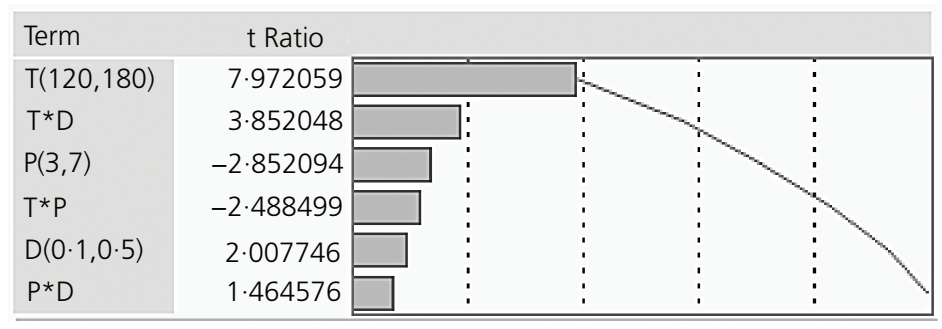

(a)

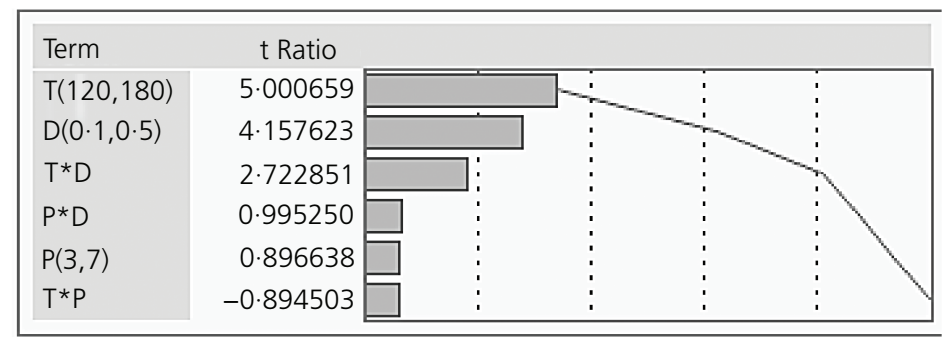

(b)

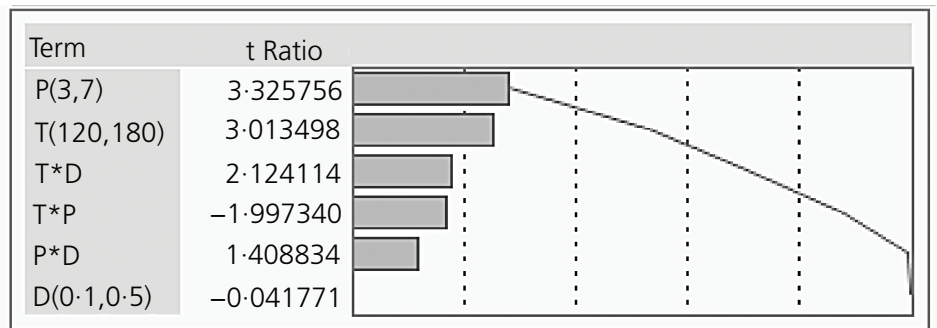

(c)

Figure 1. Pareto plot of significant factors for (a) Ortho-P, (b) ammonia and (c) VFA solubilisation, respectively

maximum SCOD of $14 \cdot 9 \pm 0 \cdot 4 \mathrm{~g} / \mathrm{L}$ was recorded at $180^{\circ} \mathrm{C}, \mathrm{pH} 3$ and $0.5 \% \mathrm{v} / \mathrm{v}$ hydrogen peroxide dosage.

Total suspended solids (TSS) concentration (Table 3) is also a factor indicative of effective solids disintegration. Reduction in TSS increases efficacy of struvite crystallisation process for nutrient recovery. The three major factors enhancing reduction in TSS were as follows, in order from the most to least significant: (i) MW heating temperature, (ii) hydrogen peroxide addition, and (iii) combined effect of MW heating and sulfuric acid addition. Similar to SCOD release, most effective TSS reduction by $63 \%$ was observed at $180^{\circ} \mathrm{C}, \mathrm{pH} 3$ and $0.5 \% \mathrm{v} / \mathrm{v}$ hydrogen peroxide resulting in a VSS/TSS ratio of $0 \cdot 99$.

The mechanism of the $\mathrm{MW} / \mathrm{H}_{2} \mathrm{O}_{2}-\mathrm{AOP}$ is similar to the wet-air oxidation process, first hydrolysing complex particulate organic slurry into simple soluble organic compounds followed by oxidation of these soluble organic components to form final products in the

\begin{tabular}{|c|c|c|c|c|c|c|c|}
\hline Run & Calcium: mg/L & Potassium: mg/L & Magnesium: mg/L & Sodium: mg/L & TCOD/TS & TSS: mg/L & VSS/TSS \\
\hline 1 & $143 \pm 18$ & $274 \pm 3$ & $216 \pm 5$ & $168 \pm 4$ & $1 \cdot 2$ & $21586 \pm 3704$ & 0.88 \\
\hline 2 & $143 \pm 20$ & $338 \pm 6$ & $273 \pm 25$ & $152 \pm 1$ & 0.9 & $25079 \pm 1429$ & 0.87 \\
\hline 3 & $172 \pm 13$ & $326 \pm 3$ & $306 \pm 14$ & $143 \pm 1$ & $1 \cdot 0$ & $27601 \pm 268$ & 0.92 \\
\hline 4 & $148 \pm 3$ & $383 \pm 20$ & $186 \pm 11$ & $203 \pm 13$ & $1 \cdot 1$ & $24552 \pm 2722$ & 0.90 \\
\hline 5 & $201 \pm 2$ & $377 \pm 12$ & $359 \pm 1$ & $158 \pm 3$ & $1 \cdot 3$ & $15113 \pm 714$ & 0.84 \\
\hline 6 & $240 \pm 3$ & $282 \pm 6$ & $294 \pm 4$ & $164 \pm 3$ & $1 \cdot 2$ & $19284 \pm 1525$ & 0.91 \\
\hline 7 & $92 \pm 11$ & $292 \pm 10$ & $199 \pm 8$ & $169 \pm 6$ & $1 \cdot 5$ & $14385 \pm 2789$ & 0.85 \\
\hline 8 & $265 \pm 3$ & $464 \pm 16$ & $322 \pm 4$ & $236 \pm 7$ & $1 \cdot 1$ & $21684 \pm 2262$ & 0.87 \\
\hline 9 & $212 \pm 18$ & $334 \pm 32$ & $348 \pm 27$ & $138 \pm 10$ & $1 \cdot 2$ & $12082 \pm 805$ & 0.99 \\
\hline
\end{tabular}

Table 3. Metal results from surface response experimental design 
Nutrient recovery from foam with

microwave treatment

More, Srinivasan, Liao et al. form of VFAs and $\mathrm{CO}_{2}$ by means of intermediate thermal decomposition step (Liao et al., 2007). Unlike ammonia and ortho$\mathrm{P}, \mathrm{pH}$ was the most significant factor in solubilising VFAs as shown in Figure 1(c) followed by MW heating temperature and combined effect of MW heating temperature and hydrogen peroxide addition. The $R^{2}$ value for VFA screening model was 0.93 indicating a good fit. Similar results were observed during studies on foam and sewage sludge after $\mathrm{MW} / \mathrm{H}_{2} \mathrm{O}_{2}$-AOP treatment (Liao et al., 2007; Lo et al., 2010). In a real-time MEBPR operation, VFAs obtained from $\mathrm{MW} / \mathrm{H}_{2} \mathrm{O}_{2}$-AOP treated foam could be recirculated to front end of the plant as a carbon source for bio-P process.

\section{Metals}

Similar to TP and TKN, metal concentrations were higher in foam than the sewage sludge (Lo et al., 2010). The metal concentrations found in the MW/ $\mathrm{H}_{2} \mathrm{O}_{2}$-AOP treated foam are given in Table 3. Maximum values for calcium, potassium and sodium were $264 \pm 3$, $464 \pm 16$ and $236 \pm 7 \mathrm{mg} / \mathrm{L}$, respectively, at $180^{\circ} \mathrm{C}, \mathrm{pH} 4$, and $0 \cdot 1 \% \mathrm{v} / \mathrm{v}$ hydrogen peroxide addition; whereas at $160^{\circ} \mathrm{C}, \mathrm{pH} 4$, and $0 \cdot 5 \% \mathrm{v} / \mathrm{v}$ hydrogen peroxide addition, the maximum magnesium concentration of $359 \pm 1 \mathrm{mg} / \mathrm{L}$ was released. Parameters affecting metal solubilisation were not same for all the metals. After MW/ $\mathrm{H}_{2} \mathrm{O}_{2}$-AOP treatment, sodium, potassium, calcium and magnesium along with intracellular material were released but only acidic conditions unbound $\mathrm{Ca}$ and $\mathrm{Mg}$ by denaturation of enzymes (Lo et al., 2010). Whereas sodium-potassium adenosine triphosphatase (Na+/K+-ATPase) located on the plasma membrane of cells facilitating movement of $\mathrm{Na}^{+}$and $\mathrm{K}^{+}$ions across cell membrane to maintain turgor pressure within cell (Skou, 1998) immediately released these ions after cell lysis. The acid addition factor $(\mathrm{pH})$ played a key role in calcium and magnesium solubilisation and hydrogen peroxide dosage was the most significant factor in potassium and sodium solubilisation, similar to Lo et al. 2010.
Magnesium concentrations in the supernatant can be increased because of the MW/ $\mathrm{H}_{2} \mathrm{O}_{2}$-AOP treatment; without $\mathrm{MW} / \mathrm{H}_{2} \mathrm{O}_{2}-\mathrm{AOP}$, external magnesium addition is necessary for struvite formation. Potassium is important to form K-struvite, another form of struvite where potassium molecule replaces ammonium molecule.

\section{Settling and dewatering}

After digestion of sewage sludge, solids processing is one of the critical aspect in a WWTP and involves around $40 \%$ of its overall operational and maintenance cost. To achieve higher degrees of solids reduction and zero sludge production is current challenge. From the results of this study, it was observed that MW treatment along with addition of strong oxidant like hydrogen peroxide and acidic $\mathrm{pH}$ play key roles in solids disintegration. Further, it also proved to be efficient in improving settling and dewatering ability of treated foam. Settling and dewatering results are shown in Figures 2 and 3, respectively. Maximum settling and dewaterability was observed at $180^{\circ} \mathrm{C}, \mathrm{pH} 3$ and $0.5 \% \mathrm{v} / \mathrm{v}$ of hydrogen peroxide dosage; $30 \cdot 5$ of $100 \mathrm{~mL}$ total volume settled in $60 \mathrm{~min}$ and CST of $19 \mathrm{~s}$ was recorded. Highest CST value of $1164 \mathrm{~s}$ was recorded for run 4 at conditions $160^{\circ} \mathrm{C}$, no acid addition and $0 \cdot 1 \%$ hydrogen peroxide dosage indicating poor dewatering ability. This can be because high amount of extracellular polymeric substances (EPS) released owing to bacterial cell break down and residual solids after MW treatment caused blockage of pores within filter paper preventing escape of water from treated solution (Chan et al., 2010). Analysis of the data showed hydrogen peroxide addition to be the most influencing factor in yielding settling results followed by MW heating temperature and combined effect of temperature and hydrogen peroxide dosage. The three most significant factors for achieving good CST results were, in order from the most to least significant, (i) sulfuric acid addition, (ii) hydrogen peroxide dosage and (iii) MW heating temperature.

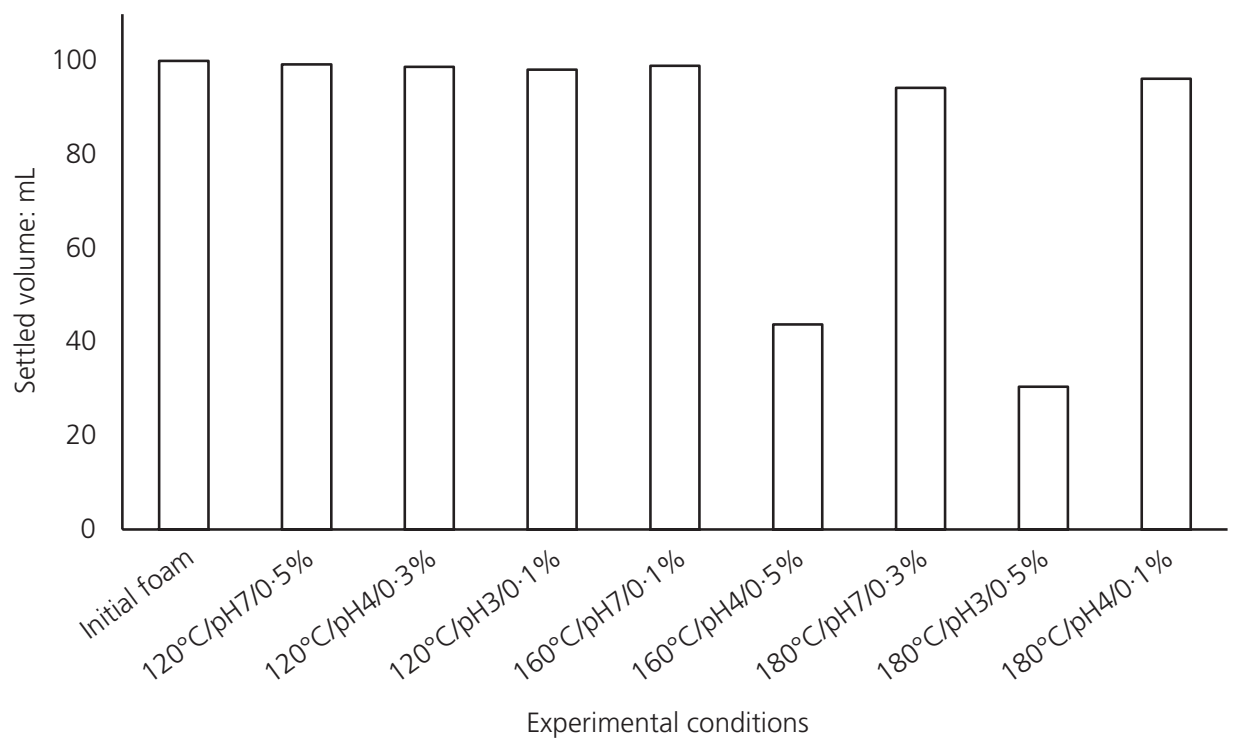

Figure 2. Settling results before and after treatment of foam 
Journal of Environmental Engineering and Science

Volume 10 Issue JS3
Nutrient recovery from foam with

microwave treatment

More, Srinivasan, Liao et al.

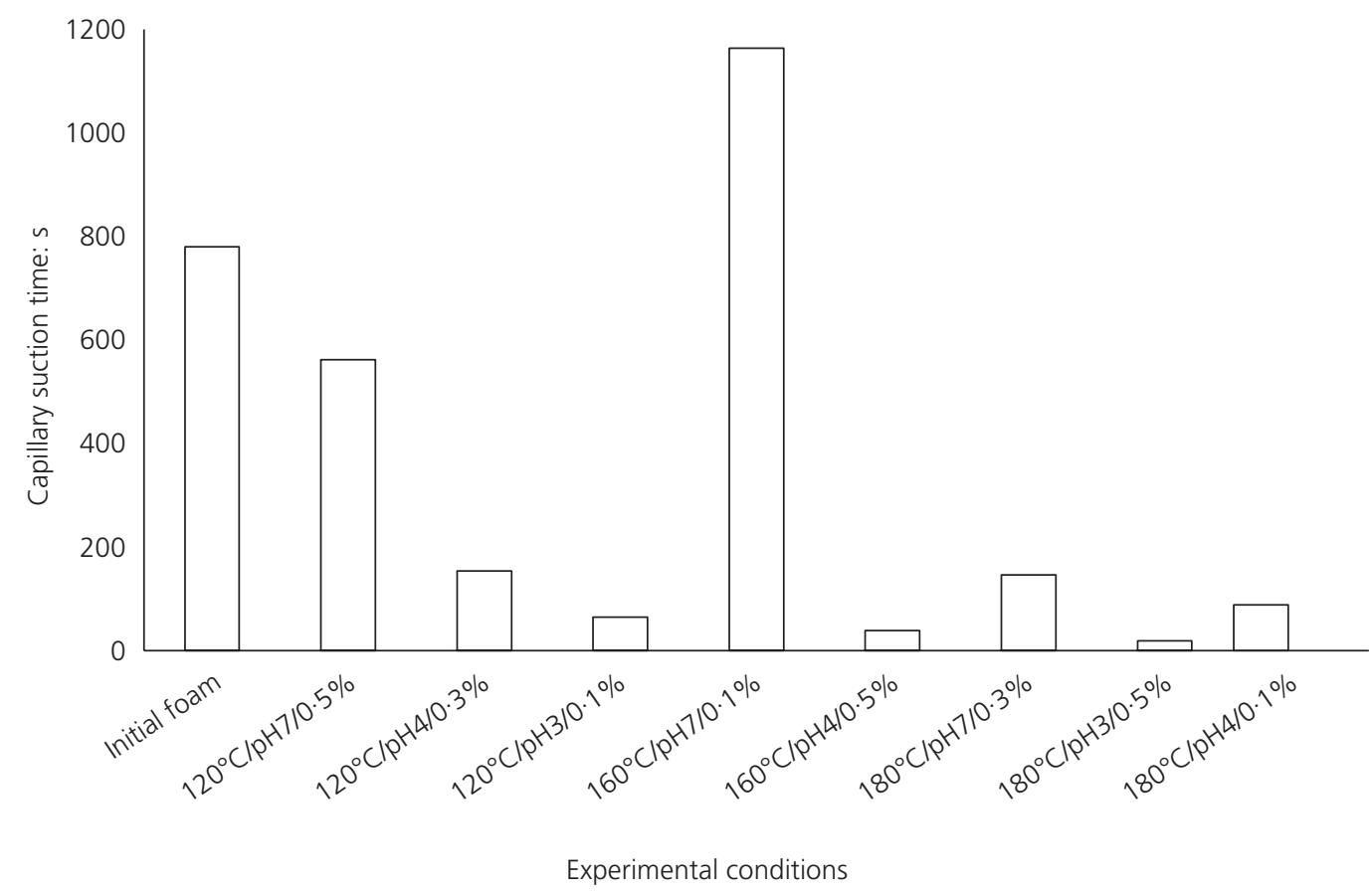

Figure 3. Dewatering results before and after treatment of foam

Results for particle size distribution analysis, as percent volume, performed on treated and untreated samples are presented in Figure 4. A right-hand-side shift in the graph of treated samples from untreated raw sample was observed indicating increase in larger-diameter particles compared to that of initial. This may be due to the re-flocculation phenomenon; compounds, such as nucleic acids, proteins carbohydrates, released from intracellular or extracellular materials act as good flocculants (Lo et al.,
2015). For the sets without any $\mathrm{pH}$ adjustment, a second smaller peak towards larger particle size was observed, which could be explained by a more pronounced re-flocculation phenomenon. Particle size increased from approximately $11-54 \mu \mathrm{m}$ in raw sample to approximately $11-115 \mu \mathrm{m}$ in treated sample at $180^{\circ} \mathrm{C}, \mathrm{pH} 3$ and $0.5 \%$ hydrogen peroxide dosage, at which highest corresponding values for settling and CST were observed. Overall results indicated that particle size increased with acid addition (lower $\mathrm{pH}$ ) and MW

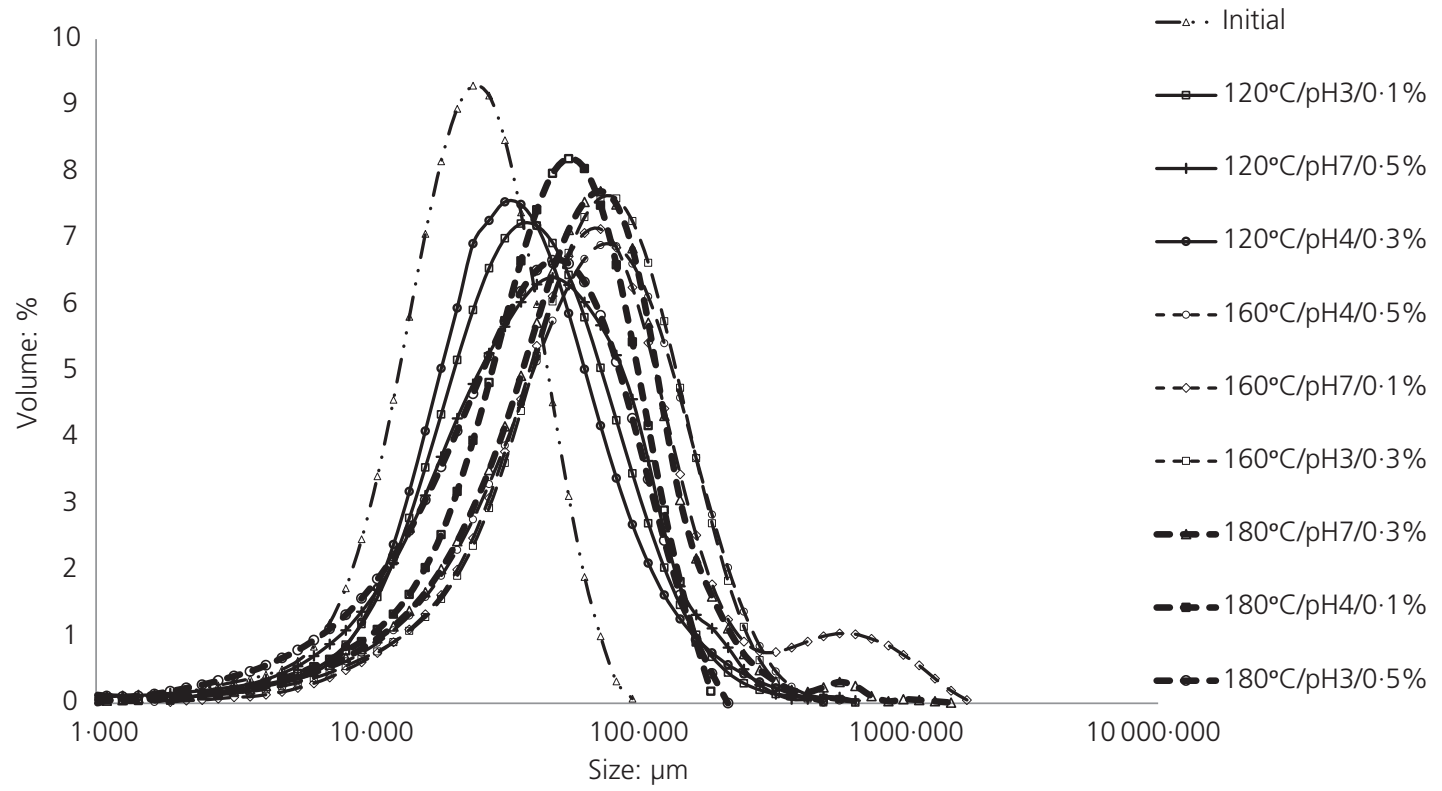

Figure 4. Particle size distribution of treated and untreated foam samples 
Journal of Environmental Engineering and

Science

Volume 10 Issue JS3
Nutrient recovery from foam with

microwave treatment

More, Srinivasan, Liao et al. heating temperature. Factors such as surface charges, quantities of ions and $\mathrm{pH}$ may also affect flocculation formation. Addition of acid to sewage sludge causes release of EPS from the bacterial flocs and enhances agglomeration of the solids improving dewatering ability of the sludge sample. This could be explained with the reduced surface charge at low $\mathrm{pH}$ owing to formation of hydronium ions, which minimises electrostatic repulsion and allows coagulation of floc increasing settling (Chan et al., 2010). It shall be noted that the $\mathrm{pH}$ range of $2 \cdot 6-3 \cdot 6$ is the iso-electric point of sewage sludge, which makes it more stable improving the dewatering ability (Neyens et al., 2003; Srinivasan et al., 2015). The resulting $\mathrm{MW} / \mathrm{H}_{2} \mathrm{O}_{2}$-AOP treated foam at $180^{\circ} \mathrm{C}, \mathrm{pH} 3$ and $0.5 \%$ hydrogen peroxide dosage also had the highest SCOD and VFA concentration and settled very fast.

\section{Conclusion}

Improved solubilisation of nutrients was observed after the $\mathrm{MW} / \mathrm{H}_{2} \mathrm{O}_{2}$-AOP treatment along with metal contents and the order of effect varied for each parameter studied. This process was effective in disintegrating solids; high SCOD and VFA were observed after the treatment. It further resulted in improved settling and dewatering ability indicating a better solids handling capability. The highest Ortho-P and SCOD concentrations of $1160 \pm 131$ and $14.9 \pm 0.4 \mathrm{~g} / \mathrm{L}$, respectively, were obtained at MW heating temperature $180^{\circ} \mathrm{C}, \mathrm{pH} 3$, and $0.5 \% \mathrm{v} / \mathrm{v}$ hydrogen peroxide dosage. About $67 \%$ of TP was solubilised after treatment at $180^{\circ} \mathrm{C} \mathrm{MW}$ heating temperature. The $\mathrm{MW} / \mathrm{H}_{2} \mathrm{O}_{2}$-AOP treatment of foam offers means to control foam, recover nutrients and efficient biosolids processing in real-time application.

\section{Acknowledgements}

The authors would like to acknowledge the research funding by the Discovery Program of the Natural Science and Engineering Research Council Canada (NSERC) and technical assistance provided by Paula Parkinson and Timothy Ma.

\section{REFERENCES}

Ahrens L, Felizeter S, Sturm R, Xie Z and Ebinghaus R (2009) Polyfluorinated compounds in waste water treatment plant effluents and surface waters along the River Elbe, Germany. Marine Pollution Bulletin 58(9): 1326-1333. See http://www.ncbi.nlm.nih.gov/pubmed/19501845 (accessed 05/03/2014).

APHA (American Public Health Association), AWWA (American Water Works Federation) and WEF (Water Environment Federation) (2005) Standard Methods for the Examination of Water and Wastewater, 21st edn. APHA, AWWF and WEF, Washington, DC, USA.

Chan WI, Liao PH and Lo KV (2010) Effects of irradiation intensity and $\mathrm{pH}$ on nutrients release and solids destruction of waste activated sludge using the microwave-enhanced advanced oxidation process. Water Environment Research 82(11): 2229-2238. See http://openurl.ingenta.com/content/ xref?genre $=$ article $\&$ issn $=1061-4303 \&$ volume $=$ 82\&issue $=11 \&$ spage $=2229$ (accessed 01/11/2014).
Di Bella G, Torregrossa M and Viviani G (2011) The role of EPS concentration in MBR foaming: analysis of a submerged pilot plant. Bioresource Technology 102(2): 1628-1635. See http://www.ncbi.nlm.nih.gov/pubmed/20933394 (accessed 02/03/2014).

Fryer M, O'Flaherty E and Gray NF (2011) Evaluating the measurement of activated sludge foam potential. Water 3(4): 424-444. See http://www.mdpi.com/2073-4441/3/1/424/ (accessed 02/03/2014).

Hall ER, Monti A and Mohn WW (2011) Production and characterization of foam in the anoxic zone of a membraneenhanced biological phosphorus removal process. Water Environment Research 83(2): 173-183. See http://openurl. ingenta.com/content/xref?genre=article $\&$ issn $=1061$ $4303 \&$ volume $=83 \&$ issue $=2$ \&spage $=173$ (accessed 02/03/2014).

Kenge AA, Liao PH and Lo KV (2009) Factors affecting microwave-enhanced advanced oxidation process for sewage sludge treatment. Journal of Environmental Science and Health. Part A, Toxic/Hazardous Substances \& Environmental Engineering 44(11): 1069-1076. See http://www.ncbi.nlm.nih.gov/pubmed/19847696 (accessed 06/11/2014).

Le Corre KS, Valsami-Jones E, Hobbs P and Parsons SA (2009)

Phosphorus recovery from wastewater by struvite crystallization: a review. Critical Reviews in Environmental Science and Technology 39(6): 433-477. See http://www. tandfonline.com/doi/abs/10.1080/10643380701640573 (accessed 21/01/2014).

Liao PH, Lo KV, Chan WI and Wong W (2007) Sludge reduction and volatile fatty acid recovery using microwave advanced oxidation process. Journal of Environmental Science and Health. Part A, Toxic/Hazardous Substances \& Environmental Engineering 42(5): 633-639. See http:// www.ncbi.nlm.nih.gov/pubmed/17454370 (accessed 06/11/2014).

Lo KV, Chan WI, Lo IW, Koch F and Liao PH (2010) Extraction of nutrients from foam in a membrane activated sludge system. Environmental Technology 31(11): 1281-1288. See http:// www.ncbi.nlm.nih.gov/pubmed/21046958 (accessed 02/03/2014).

Lo KV et al. (2011) Method and Apparatus Using Hydrogen Peroxide and Microwave System for Slurries Treatment. US Patent 20120067796, March. See http://www.google.com/ patents/US8444861\#legal-events (accessed 09/03/2014).

Lo KV, Srinivasan A, Liao PH and Bailey S (2015) Microwave oxidation treatment of sewage sludge. Journal of Environmental Science and Health, Part A 50(8): 882-889.

Machnicka A, Grübel K and Suschka J (2008) Enhanced biological phosphorus removal and recovery. Water Environment Research 80(7): 617-623. See http://search. ebscohost.com/login.aspx?direct=true $\& \mathrm{db}=\mathrm{iih} \& \mathrm{AN}=$ 34124068\&lang=es\&site=ehost-live (accessed 19/10/2014).

Mavinic DS, Koch FA and Lo KV (2007) Phosphorus recovery from anaerobic digester supernatants using a pilot-scale struvite crystallization process. Journal of Environmental 
Nutrient recovery from foam with

microwave treatment

More, Srinivasan, Liao et al.
Engineering and Science 6(5): 561-571. See http://www. icevirtuallibrary.com/content/article/10.1139/S07-007 (accessed 17/12/2014).

Neyens E, Baeyens J, Weemaes M and De Heyder B (2003) Hot acid hydrolysis as a potential treatment of thickened sewage sludge. Journal of Hazardous Materials B 98(1-3): 275-293.

SAS Institute Inc. (2013) Using JMP 11. See http://www.jmp.com/ support/downloads/pdf/jmp11/Using_JMP.pdf (accessed 19/10/2014).

Sepulvado JG, Blaine AC, Hundal LS and Higgins CP (2011) Occurrence and fate of perfluorochemicals in soil following the land application of municipal biosolids. Environmental Science \& Technology 45(19): 8106-8112. See http://www. ncbi.nlm.nih.gov/pubmed/21446724 (accessed 19/10/2014).

Skou JC (1998) The influence of some cations on an adenosine triphosphatase from peripheral nerves. Journal of the American Society of Nephrology 9(11): 2170-2177.

Suschka J, Kowalski E and Grubel K (2009) Involvement of filamentous bacteria in the phosphorus recovery cycle. In Nutrient Recovery from Wastewater Streams International Conference, Nutrient Recovery from Wastewater Streams (Ken A, Mavinic DS and Koch FA (eds)). IWA Publishing, London, UK, pp. 479-488.

Srinivasan A, Young C, Liao PH and Lo KV (2015) Radiofrequency-oxidation treatment of sewage sludge. Chemosphere 141: 212-218.

Weinberg I, Dreyer A and Ebinghaus R (2011) Waste water treatment plants as sources of polyfluorinated compounds, polybrominated diphenyl ethers and musk fragrances to ambient air. Environmental Pollution 159(1): 125-132. See http://www.ncbi.nlm.nih.gov/pubmed/20951480 (accessed 05/03/2014).

Wong WT, Lo KV and Liao PH (2007) Factors affecting nutrient solubilization from sewage sludge using microwave-enhanced advanced oxidation process. Journal of Environmental Science and Health. Part A, Toxic/Hazardous Substances \& Environmental Engineering 42(6): 825-829. See http://www. ncbi.nlm.nih.gov/pubmed/17474010 (accessed 18/10/2014).

Yawson SK, Liao PH and Lo KV (2011) Two-stage dilute acid hydrolysis of dairy manure for nutrient release, solids reduction and reducing sugar production. Natural Resources 2(4): 224-233. See http://www.scirp.org/journal/ PaperDownload.aspx?DOI=10.4236/nr.2011.24028 (accessed 02/03/2014).

Yi WG, Lo KV and Mavinic DS (2014) Effects of microwave, ultrasonic and enzymatic treatment on chemical and physical properties of waste-activated sludge. Journal of Environmental Science and Health - Part A Toxic/Hazardous Substances and Environmental Engineering 49(February 2015): 203-209. See http://dx.doi.org/10.1080/ 10934529.2013.838880 (accessed 19/10/2014).

Yin GQ, Liao PH and Lo KV (2007) An ozone/hydrogen peroxide/ microwave-enhanced advanced oxidation process for sewage sludge treatment. Journal of Environmental Science and Health. Part A, Toxic/Hazardous Substances \& Environmental Engineering 42(8): 1177-1181. See http://www.ncbi.nlm.nih. gov/pubmed/17616891 (accessed 08/03/2014).

Yin GQ, Liao PH and Lo KV (2008) Microwave enhanced advanced oxidation process for sewage sludge treatment: the effects of ozone addition. Journal of Environmental Engineering and Science 7(2): 115-122. See http://www. icevirtuallibrary.com/content/article/10.1139/S07-042 (accessed 08/03/2014).

Yu Y, Chan WI, Liao PH and Lo KV (2010) Disinfection and solubilization of sewage sludge using the microwave enhanced advanced oxidation process. Journal of Hazardous Materials 181(1-3): 1143-1147. See http://www.ncbi.nlm.nih. gov/pubmed/20591564 (accessed 08/03/2014). 